\title{
Lucha de clases y acumulación de capital en Argentina 1973-1983: discusiones a partir de los estudios sobre la acción política obrera
}

\author{
Class struggle and capital accumulation in Argentina 1973-1983: discussions \\ based on studies of political labor action
}

\author{
Sebastián Guevara*
}

\begin{abstract}
Resumen: La lucha de clases en la Argentina de 1973 a 1983 pasó, de un proceso de creciente y compleja movilización política obrera, a su casi completa paralización a través de la represión terrorista del Estado. Este contrastante curso seguido por la lucha de clases ha sido objeto de numerosos estudios que intentan avanzar en su explicación. En este trabajo se presentan sistematizados y se ponen en discusión algunos de los argumentos desarrollados en esos estudios con la finalidad de aportar a una explicación integral que trascienda más allá de las inmediatas voluntades de los actores históricos.
\end{abstract}

Palabras clave: lucha de clases, acumulación de capital, dictadura militar, acción obrera

\begin{abstract}
The class struggle in Argentina from 1973 to 1983 passed, from a process of increasing and complex political mobilization, to its quasi complete paralysis through the state's terrorist repression. This contrasting course followed by the class struggle has been the object of numerous studies that try to advance in their explanation. In this paper, some of the arguments developed in these studies are systematized and discussed, in order to contribute to an integral explanation that transcends beyond the immediate will of the historical actors.
\end{abstract}

Keywords: class struggle, capital accumulation, military dictatorship, labor action

Recibido: 29 noviembre 2016

Aceptado: 17 marzo 2017

\footnotetext{
* Argentino, Doctor en Ciencias Sociales por la Universidad de Buenos Aires, Profesor de la Universidad de Buenos Aires e Investigador del Consejo Nacional de Investigaciones Científicas y Técnicas con asiento en el Centro de Estudios e Investigaciones Laborales. Proyecto: “Acción gremial y represión en el lugar de trabajo. Estudio comparativo sobre la militancia obrera en la industria automotriz bonaerense (1973-1983)", ANCyT, PICT1155/2012, duración 2014-2016. sebastianlguevara@gmail.com
} 


\section{Introducción}

La década que se inició con el retorno del peronismo al poder en 1973 y se cerró con el fin de la dictadura militar caracterizada por el proceso sistemático de represión clandestina en 1983, mostró los extremos más disímiles entre las formas políticas adoptadas por el proceso de vida social en Argentina. En 1973 se abrió un proceso de restauración democrática que estuvo signado por el avance creciente de la movilización política, con un despliegue inédito de formas de organización, participación y acción por parte de los trabajadores. Y fue cerrado, a partir de 1976, con la prohibición de toda forma de acción política a través del terrorismo ejercido desde el Estado, que logró desmovilizar (casi) absolutamente a los trabajadores.

Históricamente los trabajadores en Argentina han desplegado su acción política y sindical pesando de modo significativo sobre el conjunto del sistema político. Sin embargo, el acelerado dinamismo que se dio en los últimos años de la década de 1960 y en los primeros años de la siguiente, profundizó la complejidad de las expresiones políticas obreras y desarrolló nuevas formas de realización y organización de esas acciones: aparecieron y se extendieron organizaciones que desplegaron la lucha armada, se multiplicaron las corrientes políticas y sindicales con inserción en la actividad gremial de base que cuestionaron a, y compitieron con, las dirigencias sindicales tradicionales, etc.. Esa aceleración resultó en una nueva conmoción del sistema político, que tuvo su momento más destacado entre los años 1975 y 1976.

Dicho dinamismo se enfrentó, a su vez, a una creciente represión por parte de los representantes directos del capital y por parte del Estado durante el gobierno democrático; y encontró su punto más expresivo en la instauración de los métodos del terrorismo estatal durante la dictadura militar. Esa creciente represión fue revirtiendo, además de la movilización política general, el proceso de autonomía y cuestionamiento al interior de las organizaciones gremiales abierto en los años anteriores.

Sin embargo y a pesar de las muy marcadas diferencias entre las formas políticas desarrolladas por la lucha de clases en el período que va de 1973 a 1976 y desde entonces hasta 1983, se pueden identificar elementos que refieren a una unidad subyacente a ambos momentos. La presencia durante el gobierno democrático del creciente proceso represivo (con el objetivo de controlar la movilización), de las políticas tendientes a la centralización sindical (con la intención de detener el proceso de autonomía y cuestionamiento existente) y los intentos de dar curso a un agudo ajuste económico (a través del "Plan Rodrigo" en 1975 y del "Plan Mondelli" en 1976, que serían finalmente realizados por el gobierno militar); así como el despliegue de acciones dispersas de resistencia y la lenta reconstitución de organizaciones obreras (claramente debilitadas) durante la dictadura militar, manifiestan la existencia de una continuidad más profunda en el proceso de producción de la vida social en Argentina ${ }^{1}$.

El objetivo general de nuestra investigación -que trasciende más allá del alcance de este trabajo- es ahondar en la identificación de dicha unidad, buscando avanzar en el

\footnotetext{
${ }^{1}$ Sebastián Guevara, "Conflictos obreros en la industria automotriz argentina: análisis de la acción obrera en la planta de Ford antes y después del golpe militar de 1976", en VIII Congreso ALAST, Buenos Aires, 2016.
} 
conocimiento sobre las razones de tan profundo cambio en las formas políticas que caracterizaron (y perduraron) en el proceso social argentino; a través del desarrollo de una perspectiva que permita desenvolver el análisis más allá de la explicación inmediata basada en las voluntades que guiaron las acciones que dieron curso a los acontecimientos en esos años.

Para ello, en este trabajo, sistematizamos y ponemos en discusión un conjunto de argumentos que son utilizados para analizar el periodo en cuestión, en pos de delimitar los aportes y las limitaciones de las explicaciones desplegadas hasta el momento como paso necesario para avanzar en el desarrollo de dicha perspectiva.

Sintéticamente, tal conjunto de argumentos está conformado por: aquellos que destacan el avance de las organizaciones de izquierda al interior del movimiento obrero como expresión inmediata del avance de una amenaza revolucionaria al orden social capitalista y la respuesta de orden establecida por la derecha; los que entienden que el eje del análisis pasa por el enfrentamiento entre diversos "modelos de acumulación de capital" impulsados por distintos actores sociales que en su enfrentamiento protagonizaron los procesos de movilización y desmovilización; y, finalmente, aquellos que priorizan las influencias que la crisis internacional y la reestructuración resultante ejerció sobre las relaciones entre las clases en el país.

\section{El peso de las organizaciones de izquierda y la amenaza revolucionaria}

De la gran variedad de trabajos dedicados a analizar el proceso de movilización política (y particularmente su compleja dimensión sindical) que se produjeron en la última década, son quizás los publicados por Aguirre-Werner ${ }^{2}$ y Lobbë ${ }^{3}$ los que exponen más claramente el argumento que pone el foco en el papel jugado por las organizaciones de izquierda en dicha movilización y su consecuente desarrollo como una amenaza para el orden social.

Estos autores plantean que desde el año 1969 se experimentó un marcado ascenso de la actividad del movimiento obrero. El cual a partir del "Cordobazo", con la emergencia de organizaciones revolucionarias y el desarrollo al interior del movimiento obrero de corrientes políticas combativas y clasistas, se transformó en un ascenso revolucionario. El cual se dio en el marco de la crisis que se estaba desarrollando en el mundo, que obligó a los países "semi-coloniales" a reducir la participación de los trabajadores en el ingreso nacional, terminando de ese modo con la movilidad social que las había caracterizado hasta ese momento ${ }^{4}$. La movilización social se aceleró como respuesta a la "recurrente crisis" en la que entró el capitalismo argentino ${ }^{5}$.

Simultáneamente, el marco de la crisis agudizó las tensiones al interior de la "clase dominante", que desde el momento de la entrada masiva del capital extranjero (fines de los

\footnotetext{
${ }^{2}$ Facundo Aguirre y Ruth Werner, Insurgencia Obrera en la Argentina 1969-1976. Clasismo, coordinadoras interfabriles y estrategias de la izquierda, Buenos Aires, Ediciones IPS, 2009.

${ }^{3}$ Hector Löbbe, La guerrilla fabril. Clase Obrera e izquierda en la Coordinadora de Zona Norte del Gran Buenos Aires (1975-1976), Buenos Aires, Ediciones RyR, 2009.

${ }^{4}$ Aguirre y Werner, op.cit., 39.

${ }^{5}$ Löbbe, op.cit., 35.
} 
años '50) no había logrado establecer una situación de equilibrio entre sus facciones (el capital extranjero había ido imponiendo su predominio económico pero sin lograr establecer un poder hegemónico sobre el conjunto). Esta agudización, al profundizar la división dentro de la "clase dominante", aportó otro elemento para que la crisis adoptara un carácter orgánico y se abriera así la etapa revolucionaria ${ }^{6}$.

Frente a la incapacidad de la "Revolución Argentina" para frenar el ascenso de la movilización obrera, estos autores, destacan el retorno de Perón al sistema político como el intento de contener y desviar el movimiento de sus perspectivas revolucionarias. El creciente peso de las organizaciones de izquierda en ese movimiento, al impedir que se lograra el equilibrio de fuerzas al interior de la "clase dominante", amenazaba la viabilidad del capitalismo argentino ${ }^{7}$.

Sin embargo el gobierno peronista, que después del necesario momento "frente populista" se manifestó abiertamente como el partido del orden, también fracasó en el intento des movilizador. Para llevar adelante dicha contención el peronismo debía anular el protagonismo adquirido por el movimiento obrero que, organizado crecientemente a través de organismos gremiales de base recuperados para los intereses históricos de la clase obrera (impulsada por fuerzas de izquierda), protagonizó acontecimientos como el "Villazo" o las “jornadas de junio julio de 1975", que ponían en cuestión la dirección política monolítica del peronismo sobre el movimiento obrero. Estos acontecimientos expresaban el proceso de escisión creciente de la clase obrera respecto del peronismo en el gobierno y, con ello, la potencialidad política y el poder social de la clase obrera como fuerza independiente ${ }^{8}$. Las organizaciones de base en el movimiento sindical (que tendían a desbordar a sus direcciones tradicionales) ponían en jaque el control de la producción social, amenazando así la autoridad en los lugares de trabajo, con ello a la propiedad privada y al sistema en su conjunto 9 .

De modo tal que, frente al fracaso del peronismo para detener el avance de la amenaza revolucionaria, el golpe militar de 1976 vino a resolver, por la vía del terrorismo de Estado, tanto la crisis orgánica presente en el capitalismo argentino como la situación revolucionaria que ésta había abierto. A partir de la desmovilización de la clase obrera, "el sector más concentrado y poderoso de la gran burguesía” logró, finalmente, imponer su hegemonía ${ }^{10}$.

\footnotetext{
${ }_{7}^{6}$ Aguirre y Werner, op.cit., 40-47.

7،"Es por eso, también, que puede decirse que la ofensiva de las masas vino a cuestionar al conjunto del orden burgués: porque planteó políticamente (es decir, en el terreno nada especulativo de la práctica históricopolítica) la necesidad de resolver la relación de fuerzas cuyo nuevo "equilibrio", tumultuosamente puesto de manifiesto en aquellos días, era el inestable equilibrio de la crisis orgánica del capitalismo argentino." Aguirre y Werner, op.cit., 63. También en Aguirre y Werner, op.cit., 49-53 y Löbbe, op.cit., 251.

${ }^{8}$ Ibid., 36.

9،... ese proceso fue consecuencia de la acción consciente de la labor de recuperación de los organismos fabriles y coordinación impulsada por las fuerzas de izquierda. (...) y convirtieron ese accionar en uno de los desafíos más serios que recibió el sistema capitalista en la Argentina.” Löbbe, op.cit., 284-285.

10 ... "[el golpe militar fue un] acto tardío del Estado y la burguesía argentina. Impedidos de actuar por una relación de fuerzas que desde 1969 destacaba la iniciativa de los trabajadores, lo hicieron frente a la necesidad vital de responder a la enorme crisis que atravesaba el capitalismo y el fracaso de las políticas de contención
} 
En síntesis, la crisis orgánica del capitalismo argentino sumada al ascenso de masas caracterizado por el peso adquirido por las organizaciones de izquierda -fenómenos que se profundizaban mediante su influencia mutua-, desembocaron en una crisis revolucionaria que, frente a la incapacidad del peronismo para desviarla o contenerla, determinó al terrorismo de Estado impuesto a través del golpe militar de 1976 como el mecanismo para, al mismo tiempo, conjurar la amenaza revolucionaria (terminando con la movilización masiva) y permitir el equilibrio hegemónico de las distintas facciones de las "clases dominantes"(cerrando la crisis orgánica).

Una de las limitaciones de este análisis es que no plantea qué relación existe entre ambas dimensiones del proceso social. Es decir: no queda claro cuál es el origen de la crisis orgánica y qué relación tiene con el ascenso de masas, del cual tampoco queda claro el origen, que determinarán el carácter revolucionario de la situación y con él el carácter terrorista de la resolución.

El ascenso de masas podría aparecer explicado (desde los trabajos presentados) como la reacción de la población obrera de los países "semi-coloniales" frente a su retroceso en la participación en el ingreso nacional y el fin de la movilidad social, impuestos por la crisis internacional "en el marco" de la crisis orgánica y el agotamiento estructural del capitalismo argentino ${ }^{11}$.

Por otro lado, la crisis orgánica (ya que del agotamiento estructural del capitalismo argentino no hay más mención) podría aparecer explicada por la división y el enfrentamiento al interior de las clases dominantes, imposibilitadas de alcanzar una situación de equilibrio (hegemónico) por chocar contra la irrupción de las masas movilizadas ${ }^{12}$.

Sin embargo, estas posibles explicaciones -que se suponen mutuamente-, al no poder dar cuenta de sus orígenes dejan a su vez sin explicación el resultado de su combinación, esto es: la situación revolucionaria.

El empobrecimiento relativo de la clase obrera y la concentración de la riqueza en manos de los poseedores del capital constituye la ley absoluta, general, de la acumulación capitalista $^{13}$. De modo que, si esta fuera la explicación del origen de los procesos de movilización de masas, estaríamos frente a un proceso de carácter permanente ${ }^{14}$.

A su vez, en el modo de producción capitalista el antagonismo social no se reduce a la relación entre los poseedores del capital y los de la fuerza de trabajo sino que todas las relaciones son antagónicas. Entre los miembros de la misma clase se desarrolla bajo la

encarnadas en el peronismo. De ahí su virulencia criminal y su carácter rapaz.” Aguirre y Werner, op.cit., 18 y Löbbe, op.cit., 235

${ }^{11}$ Aguirre y Werner, op.cit., 34 y 41.

${ }^{12}$ Ibid., 48.

${ }^{13}$ Carlos Marx, El Capital. Crítica de la economía política.Tomo I. México, D.F.: Fondo de Cultura Económica, [1867] 2014, 574-575.

${ }^{14}$ Algo de esto parecería reflejarse en el planteo analizado, ya que se sostiene que: en Argentina después de 1955 hubo dos ascensos de masas previos al Cordobazo (en 1956-1959 y en 1961-1965) que se agregan al experimentado desde 1969 hasta 1976. Aguirre y Werner, op.cit, 35.

Es decir que en la Argentina posterior al derrocamiento de Perón en 1955 se vivió virtualmente en un proceso de ascenso de masas constante. 
forma de la competencia y ésta se expresa en múltiples formas de enfrentamiento entre sus fracciones. Si la situación de crisis orgánica se explicara por la presencia de estos enfrentamientos el capitalismo viviría crónicamente en ella.

De modo que, si la crisis y el ascenso de masas fuesen fenómenos crónicos, sería imposible la explicación de por qué en determinados momentos históricos la acción de la clase obrera desarrolla características revolucionarias, que es precisamente lo que estos argumentos buscan explicar. Salvo que se apele a la intervención de las organizaciones revolucionarias (con estrategias revolucionarias, con orientaciones clasistas y combativas, que guíen la escisión ideológica con las direcciones que buscan contener el movimiento revolucionario, etc.). Sin embargo, esta apelación, no hace más que reponer la pregunta sobre el origen de dicha intervención, por qué crece el peso de esas organizaciones, por qué aumentan su participación, por qué pueden recuperarse los organismos de base, etc. en determinados momentos y no en otros.

De modo que si este argumento no puede explicar cabalmente el avance de la amenaza revolucionaria, queda también sin explicación la imposición del orden a través del golpe militar.

\section{Transformación del modelo de acumulación de capital en Argentina y la amenaza revolucionaria}

Otro de los argumentos desarrollados para analizar el proceso de movilización y desmovilización experimentado en la Argentina del último tercio del siglo XX, es el que pone el foco en los "modelos de acumulación de capital" y la lucha entre los distintos actores sociales por imponerlos. Este argumento es planteado tanto desde perspectivas que caracterizan al gobierno peronista de 1973-1976 como un intento frustrado de contener el avance de la amenaza revolucionaria como desde aquellas que entienden que, por el contrario, dicho gobierno fue una expresión (aunque contradictoria) de dicho avance. Pero en todos los casos coinciden en que el gobierno ejercido por la dictadura militar dio curso a la desmovilización política como medio para imponer un nuevo modelo de acumulación, adecuado a las nuevas condiciones imperantes en la economía mundial.

Desde la primera de las perspectivas, se analiza el retorno del peronismo al gobierno en 1973 como la resolución para la burguesía en su conjunto del problema de dominación política, abierto desde la década anterior. A través de políticas inclusivas, concesiones económicas y de las acciones tendientes al fortalecimiento de las organizaciones gremiales centralizadas, cuyo eje central estuvo en el "Pacto social" y la ley de asociaciones profesionales, el peronismo en el gobierno buscó estabilizar el orden social a través de la unificación política. Sin embargo, este intento de consolidar la dominación política (concediendo mejoras en el nivel de vida de la clase obrera) se puso en contradicción con los requerimientos de la acumulación de capital, ya que no todos los sectores de la burguesía podían compensar la caída en su tasa de ganancia a través de su relación con el Estado $^{15}$. Y esta contradicción se hizo más aguda a medida que el proceso de movilización

\footnotetext{
${ }^{15}$ Héctor Capraro, Oscar Cismondi, Roberto Esteso y Alberto Spagnolo, “Argentina: economía y política en los años setenta”, en Alberto Pla, Guillermo Almeyra, Alberto Spagnolo, Oscar Cismondi, Héctor Capraro,
} 
política se fue desarrollando como una creciente ruptura de parte del movimiento obrero con el peronismo ${ }^{16}$. Los cuestionamientos anti-burocráticos y anti-patronales que antecedieron a los políticos realizados al gobierno peronista, pusieron en jaque su capacidad de garantizar la dominación política y determinaron su caída ${ }^{17}$.

De este modo el gobierno militar que se instaura a partir del golpe vino a "restaurar los vasos comunicantes del capitalismo argentino con los mercados mundiales" a través de la adecuación de la acumulación de capital a "la tendencia económica básica del capital a escala mundial" "18. La represión sobre la clase obrera y el proceso de desmovilización política general desarrollado por la dictadura impusieron las condiciones para una nueva "fundación de la Argentina capitalista en su relación con el mercado mundial""19. Después del régimen oligárquico-liberal se produjo la industrialización sustitutiva (la argentina urbana y populista) que, una vez agotada, necesitó una nueva fundación que reordenara el capitalismo argentino. Esta reorganización se dio en el marco de la reestructuración capitalista mundial pero se impuso "en función de los intereses y perspectivas de un nuevo bloque de poder constituido por la burguesía agroexportadora (...), el capital financiero y las multinacionales." 20

En la misma línea, de enfocar la explicación del proceso de desmovilización implementado por la dictadura militar para imponer un nuevo modelo de acumulación de capital (acorde a las nuevas condiciones del mercado mundial), aunque desde una

Roberto Steso, Alejandro Dabat y Adolfo Gilly, La decada tragica. Ocho ensayos sobre la crisis argentina 1973-1983, Buenos Aires: Tierra del Fuego, 1984, 85.

${ }^{16}$ “'Con la huelga general de junio de 1975, encabezada por las comisiones Coordinadoras y desbordando a la burocracia sindical de la CGT, el proletariado se enfrentó con el gobierno peronista de Isabel Perón y derrotó su intento anticipado de imponer la política económica antipopular que luego implementaría la dictadura. Esa huelga general fue una ruptura social con el peronismo, pero no todavía una ruptura política. El golpe militar de marzo de 1976 fue, entre otras cosas, la respuesta del "partido militar" de la burguesía argentina a este desbordamiento del gobierno peronista por los trabajadores." Adolfo Gilly, "Argentina después de la dictadura (Democracia, reorganización obrera, proyecto socialista)", en Pla et. al., op.cit., 237.

17 "Esta contradictoria relación entre las necesidades de dominación política y los requerimientos de acumulación de capital se plantearán crudamente durante todo el gobierno peronista y acelerarán su caída en marzo de 1976....Toda disputa obrera, cualquiera fuera su contenido, desemboca fácilmente en un cuestionamiento al proyecto global, dada la imposibilidad de anteponer la "lógica económica", la sujeción de la práctica social del movimiento obrero a los requerimientos del capitalismo argentino."Capraro et.al., en op.cit., 85-86.

18 "En síntesis, un agudo proceso de concentración y centralización de capitales, eliminación de importantes sectores burgueses de la competencia capitalista, fortalecimiento de la gran burguesía monopolista en las distintas formas de existencias del capital....." Ibid., 90.

${ }^{19}$ Guillermo Almeyra, "La clase obrera en la Argentina actual", en Pla et.al., op.cit., 27.

${ }^{20}$ Adolfo Gilly, "Las Malvinas, una guerra del capital", en Pla et.al., op.cit., 167.

"Y, agotado ese periodo [ISI] llega ahora un nuevo reordenamiento de la economía capitalista argentina que no es, como pretenden algunos, un simple retorno al pasado ni tampoco una sumisión servil a diabólicas y omnipotentes maniobras del imperialismo, impuestas mediante la división mundial del trabajo y la internacionalización del capital. Por el contrario, dicha recomposición de la economía capitalista argentina obedece fundamentalmente a tendencias internas del propio desarrollo burgués en ese país, a fuerzas de clase nativas (las cuales, por supuesto, se ligan con el imperialismo y actúan dentro del marco fijado por el actual funcionamiento del mercado mundial y por la evolución de la lucha de clases en escala internacional).", Almeyra, op.cit., 27-28. 
perspectiva divergente respecto de la significación del gobierno peronista, se encuentra el planteo desarrollado por Basualdo Victoria que se nutre, a su vez, del planteo desarrollado por Basualdo Eduardo ${ }^{21}$. Para estos autores el peronismo representó (claro que de un modo contradictorio) el proceso de ascenso de la movilización de masas; al mismo tiempo que representó la impotencia para resistir la interrupción al proceso de industrialización sustitutiva de importaciones y su reemplazo por la acumulación por valorización financiera, que impuso la dictadura militar a partir de 1976.

Sintéticamente: se plantea que el ascenso de masas se agudizó, produciendo una radicalización creciente de la acción política de la clase obrera, a partir de la represión desarrollada por el gobierno militar de la "Revolución Argentina" desde fines de la década de 1960. Esta radicalización creciente se fue desarrollando por medio de la multiplicación de diversas corrientes gremiales y políticas que, organizando su acción centradas en el trabajo de base gremial, protagonizaron el proceso de movilización ${ }^{22}$.

Esta creciente radicalidad convergió con un fortalecimiento estructural de la posición alcanzada por la clase obrera dentro del modelo de acumulación de capital basado en la sustitución de importaciones. A partir de la denominada segunda etapa de la industrialización sustitutiva, desde 1964, se fueron reduciendo los límites con que el modelo chocaba y lo hacía caer recurrentemente en situaciones de crisis. Estas transformaciones fueron protagonizadas tanto por el capital extranjero como por la denominada oligarquía diversificada ${ }^{23}$ y permitieron que la producción industrial sustitutiva se confirmara como el eje principal de la acumulación de capital que, ya sin las limitaciones anteriores, iniciase un proceso de desarrollo, aunque de características dependientes y asociadas $^{24}$. El crecimiento experimentado en aquellos años se caracterizó por la suba acelerada del empleo (principalmente industrial) que redundó en una disminución relativa de la productividad, disminuyendo la presión ejercida sobre los trabajadores en activo (como producto de la baja desocupación) y fortaleciendo, por tanto, la posición de los trabajadores y sus organizaciones gremiales dentro de los lugares de trabajo. Además las características desarrolladas por el proceso de industrialización sustitutiva ubicaban a los trabajadores (especialmente a los del sector industrial) en una posición estratégica. Eran los

\footnotetext{
${ }^{21}$ Victoria Basualdo. "Los delegados y las comisiones internas en la historia argentina: 1943-2007", en Daniel Azpiazu, Martin Schorr y Victoria Basualdo, La industria y el sindicalismo de base en la Argentina, Buenos Aires, Cara o Ceca, 2010. Eduardo Basualdo, Sistema político y modelo de acumulación en la Argentina, Bernal, Universidad Nacional de Quilmes Ediciones, 2001. Eduardo Basualdo, Estudios de Historia Económica Argentina: desde mediados del siglo XX a la actualidad, Buenos Aires, Siglo Veintiuno editores, 2010 .

${ }^{22}$ Basualdo, V., op.cit., 125.

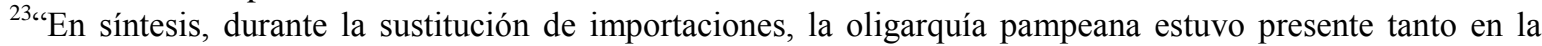
producción agropecuaria, de la que ejercía su predominio tradicional, como en la producción industrial, de la que compartía, como socio menor del capital extranjero, el predominio sectorial.” Basualdo E., op.cit., 92,93. 24 “... la producción industrial fue la actividad más dinámica con una significativa generación de empleo y la base de sustentación principal del mercado de trabajo formal en la Argentina. Podría decirse que... [se trató] de una dinámica más aproximada a lo que en el pensamiento latinoamericano se denominó un desarrollo dependiente asociado pero que, en el caso argentino, reconoce una particularidad: las fracciones empresariales predominantes en la economía interna eran tanto el capital extranjero (...) como la oligarquía diversificada (...)." Basualdo E., op.cit., 106.
} 
encargados de realizar el trabajo en las actividades centrales y más dinámicas de la economía y, a su vez, constituían el grueso del mercado interno donde se comercializaban los productos que resultaban de ésta. Este fortalecimiento estructural de la clase obrera se expresó en la participación que ésta tuvo en el producto total de la economía, pasando del $39 \%$ en 1964 al $48 \%$ en $1974^{25}$.

Simultáneamente, el éxito relativo de la segunda etapa de la industrialización sustitutiva eliminó todos los factores que hasta entonces venían oscureciendo la contradicción existente entre capital y trabajo ${ }^{26}$. De modo que estas transformaciones alimentaron a su vez al proceso de radicalización que estaba protagonizando la clase obrera en Argentina.

El gobierno peronista, que expresaba contradictoriamente, según estos autores, esa convergencia entre la radicalidad política y el fortalecimiento de la clase obrera, implicó una amenaza de desplazamiento del papel principal jugado tanto por el capital extranjero como por la oligarquía diversificada, a pesar de que el nuevo salto en el modelo de acumulación se había realizado por un Estado colonizado por estos sectores dominantes ${ }^{27}$.

De este modo el golpe militar de 1976 quedó determinado como una revancha clasista que (impulsada por un profundo resentimiento de clase ${ }^{28}$ tuvo por objeto poner fin a la confluencia entre estos procesos de radicalización política y de fortalecimiento estructural relativo de la clase obrera, y eliminar la amenaza y el obstáculo que constituían al proceso de acumulación de capital en Argentina. Es decir que, la dictadura militar a través del terrorismo de Estado no se limitó a desmovilizar políticamente a la clase obrera atacando sus organizaciones, militantes y activistas, sino que promovió cambios generales en la acumulación de capital, interrumpiendo la industrialización sustitutiva e instaurando la valorización financiera, que modificaron profundamente la relación capital/trabajo, buscando eliminar las bases estructurales de esta amenaza ${ }^{29}$.

\footnotetext{
${ }^{25}$ Basualdo, V., op.cit., 103, 116.

26، Por estas transformaciones, desde mediados de la década del sesenta las contradicciones entre capital y trabajo, al no estar opacadas por las reiteradas crisis económicas, fueron percibidas como tales en la práctica cotidiana de los sectores populares. (...) a partir del derrocamiento del peronismo, fue oscurecida por la irrupción de reiteradas crisis económicas y, finalmente, en el último período de la segunda etapa de sustitución de importaciones, se expresó diáfanamente, sin estar distorsionada por otros factores sociales." Basualdo E., op.cit., 105.

${ }^{27}$ “A comienzos de los años setenta, las condiciones estructurales vigentes durante los primeros gobiernos peronistas ya no existían, en tanto el nuevo salto en la sustitución de importaciones ya se había llevado a cabo, pero no conducido por el Estado sino por el capital extranjero que, junto a la oligarquía diversificada, habían "colonizado" el aparato estatal. Bajo el nuevo contexto económico, todo intento de reproducir esas primeras experiencias implicaba desplazar tanto al capital extranjero como a la oligarquía diversificada del control sobre las producciones centrales mediante el avance de la propiedad estatal y la burguesía nacional, e implementar una redistribución del ingreso hacia los sectores asalariados influenciada por el abaratamiento de los bienes salarios y la redefinición del patrón de crecimiento económico.” Basualdo E.,op.cit., 107.

${ }^{28} \mathrm{El}$ accionar del gobierno militar "sólo puede entenderse como una revancha oligárquica sin precedente históricos en el país, acorde con el profundo resentimiento que guardaba la oligarquía nativa hacia la clase trabajadora argentina.” Basualdo E., op. cit., 117.

${ }^{29}$ “La dictadura (...) impone un comportamiento nuevo que está basado en la valorización financiera." Basualdo E., 2001, op.cit, 30.
} 
La voluntad política de sectores dominantes (los intereses del bloque de poder), modificando las alianzas entre clases y fracciones de clase existentes hasta entonces, aparece así explicando el movimiento de la acumulación de capital (sustitución de un modelo de acumulación por otro, nueva fundación o reordenamiento del capitalismo local, etc.). La centralización del capital -por caso-, que elimina en su desarrollo a capitales individuales, que constituye una tendencia general y permanente del modo de producción capitalista $^{30}$, aparece -en estos planteos- respondiendo a la voluntad política de las fracciones de clase que se imponen en sus disputas. Así, la "desindustrialización" que implica el nuevo patrón de acumulación impuesto, complementa el objetivo de profundizar el disciplinamiento social. Convergiendo con el terrorismo de Estado en el conjuro de la amenaza revolucionaria e imposición de las nuevas condiciones para la valorización del valor.

Estos argumentos parecen presentar una base más sólida para explicar el proceso de movilización política bajo estudio. El fortalecimiento de las organizaciones obreras aparece respaldado por el lugar que ocupan en el proceso de producción de la vida social, organizado a través de los distintos modelos que adopta la acumulación de capital. Sin embargo, al avanzar en el análisis sobre la acumulación de capital este proceso aparece explicado, en última instancia, por la voluntad inmediata de los actores sociales. De modo que, la pregunta sobre el origen de tal voluntad vuelve a hacerse presente. Y, más concretamente, emerge la necesidad de indagar sobre qué razones históricas explican que esas voluntades se impongan, o no, en determinado momento particular.

Por ejemplo, de acuerdo a uno de estos planteos, la imposición del modelo de valorización financiera constituyó una revancha clasista, impulsada por el resentimiento histórico acumulado por la oligarquía argentina contra la clase obrera y fue, a su vez, el mecanismo para conjurar la amenaza que esta última significaba para el orden capitalista local. Esta condición de amenaza se desarrolló a través de la confluencia de dos aspectos del proceso social. Por la fortaleza de la posición estructural de los trabajadores, que se consolidó junto con el nuevo salto de la industrialización sustitutiva (post-1964). Y por la radicalización política de los trabajadores que fue alimentada con el éxito relativo de ese nuevo salto -que terminó de sacar del medio los factores sociales que distorsionaban la visibilidad de la contradicción entre el capital y el trabajo. Pero este salto que consolidó el proceso de acumulación de capital vía sustitución de importaciones como un relativamente exitoso caso de desarrollo dependiente asociado fue llevado adelante por quienes se constituyeron como sus principales beneficiarios, a saber: el capital extranjero en alianza con la oligarquía diversificada. Es decir que fueron los propios sectores dominantes en persecución de sus intereses inmediatos quienes consolidaron un modelo de acumulación que, al establecer las condiciones necesaria para garantizar sus sustentabilidad en el tiempo

\footnotetext{
"Sobre la base de estas concepciones y de estos alineamiento, los sectores dominantes, a través del terrorismo de Estado que ejerció la dictadura militar, le impusieron a la sociedad argentina un nuevo patrón de acumulación de capital cuyo núcleo central fueron las políticas económicas y un nuevo comportamiento estatal.” Basulado E., 2010, op.cit., 116, 129.

${ }^{30}$ Independientemente de que el curso, la velocidad y la oportunidad de esa centralización este determinado por el movimiento general de la acumulación (haciéndose más agudo en los momentos de crisis, más lento en los momentos de expansión general, etc.).
} 
(no estaba agotado) fortaleció y permitió el acceso al manejo del estado del actor social que iba a amenazar sus intereses. Recién cuando la organización política del proceso social llegó a esa instancia (el retorno del peronismo al gobierno en 1973) resolvieron interrumpir el patrón de acumulación que los tenía como principales beneficiarios para disciplinar a los sectores amenazantes.

De este modo el argumento que se apoya sobre la voluntad inmediata de los actores sociales para explicar el movimiento de la producción social deja una serie de mediaciones sin una explicación consistente.

Adicionalmente, el punto de explicar el desarrollo de la radicalidad política sobre la consolidación exitosa de la segunda etapa de industrialización sustitutiva, a pesar de dar la impresión de otorgar una base más consistente, presenta otro ángulo para analizar las dificultades señaladas.

La relación entre el capital y el trabajo es entendida como estructuralmente antagónica en el capitalismo, sin embargo durante la primera etapa del modelo sustitutivo base de la alianza policlasista en la década de 1940- ese antagonismo se vio opacado por la política de distribución del ingreso de Perón. Luego del derrocamiento del peronismo, cuando la política distributiva fue eliminada y las crisis económicas se repitieron periódicamente y resultaron en una recurrente caída de los salarios y del empleo, el antagonismo de clases continuó opacado, ahora por las crisis. Para, finalmente, expresarse diáfanamente cuando la acumulación de capital vía el modelo de sustitución de importaciones inició un crecimiento relativamente constante (con crisis menos agudas) y sin límites a la vista. ¿Cómo se explica este comportamiento? No parece adelantar mucho más el expediente de recurrir a la existencia de una histórica dualidad en la conciencia política de la clase obrera, una conciliadora (conservadora) y otra combativa (popular y antiimperialista). De modo que al imponerse una o la otra se explicaría el desarrollo dominante de acciones de tipo reformista o revolucionarias por parte de la clase obrera en Argentina. Además de la pregunta necesariamente previa sobre la razón de la existencia de estos distintos tipos de conciencia, su determinación y desarrollo (que requieren un tratamiento detenido y más pormenorizado que el que se puede intentar en este trabajo), este camino deja sin explicación el porqué de la imposición de una u otra de estas formas de conciencia en los distintos momentos históricos atravesados por el movimiento social.

Otra observación posible a este tipo de argumentos es que, al poner el eje de la explicación en el accionar de los actores sociales, parece que el movimiento de la sociedad depende del resultado del enfrentamiento entre la clase obrera y los distintos sectores de la clase capitalista. Sin embargo, al analizarlo detenidamente aparece la imagen de un enfrentamiento entre un actor que actúa de manera independiente, persiguiendo sus intereses inmediatos e históricos -la clase capitalista- y otro actor que actúa como variable dependiente que, en pos de sus intereses inmediatos, responde a los ofrecimientos realizados por distintos sectores dominantes que lo necesitan para imponerse, o no, en sus enfrentamiento intra-clase. Y que, en última instancia, son esos enfrentamientos de fracciones al interior de la clase capitalista los que explican el movimiento general, de la acumulación de capital y, con ellos, de la sociedad. 


\section{Transformaciones en la acumulación mundial del capital y lucha de clases}

El movimiento experimentado por la acumulación de capital a nivel mundial también es desarrollado como un argumento para analizar la dinámica adoptada por la lucha de clases en Argentina de ese período. Las profundas transformaciones experimentadas por la economía mundial desde mediados de la década de 1970 -que se hicieron visibles en el despliegue de la crisis internacional- son puestas como eje para explicar el movimiento seguido por el proceso nacional de acumulación de capital y la lucha de clases ${ }^{31}$.

Este enfoque, que centra su explicación en la relación entre el curso seguido por la acumulación de capital en general y su movimiento en la Argentina - y tiene una reducida extensión para el análisis del proceso de movilización y desmovilización política del período bajo análisis- encuentra antecedentes (aunque con diferencias de perspectiva) en el análisis desarrollado por Peralta Ramos a principios de la década de $1970^{32}$.

Allí se argumenta que las distintas etapas que experimenta la acumulación de capital en la Argentina, así como las alianzas de clases que las llevan adelante, se explican por su relación con el movimiento general la acumulación de capital. Este, a su vez, es determinado por las diversas etapas que cursa el imperialismo, en tanto que forma de explotación de los países dependientes por parte de los países desarrollados ${ }^{33}$.

La etapa imperialista caracterizada por la exportación de capitales, bajo la forma principal de tecnología orientada a la explotación del sector manufacturero (que se desarrolló desde la segunda mitad del siglo XX) dio como resultado, en los países dominados, una industrialización basada en la importación creciente de tecnología extranjera que respondía más a las necesidades de la acumulación de los capitales imperialistas que a las necesidades locales de la acumulación ${ }^{34}$.

Así determinada, la acumulación de capital en Argentina atravesó, a su vez, una serie de etapas: desde la industrialización que basó la valorización del capital en la prolongación de la jornada social de trabajo (a través de la incorporación masiva de fuerza de trabajo), que predominó desde la década de 1930 hasta mediados de la de 1940; pasando por aquella caracterizada por la necesidad de ampliar el mercado interno -para evitar una crisis de sobreproducción- que se llevó adelante a través de la política peronista de

\footnotetext{
31، ....consideramos que tanto las transformaciones en la dinámica de la acumulación de capital como la imposición de una nueva correlación de fuerzas por la dictadura no pueden ser abstraídas de la profunda crisis de mediados de los setenta."

Valeria Ianni, “Un aporte al análisis de las causas de la ruptura histórica de marzo de 1976” en Memorias del IV Seminario Internacional Políticas de la Memoria, Buenos Aires, 2011a, 3.

${ }^{32}$ Mónica Peralta Ramos, Etapas de acumulación y alianzas de clases en la Argentina (1930-1970), Buenos Aires, Siglo Veintiuno argentina editores sa, 1972. La perspectiva sostenida por Peralta Ramos tuvo un impacto relativo bastante significativo sobre diversos actores que protagonizaron el proceso de movilización política y sufrieron la represión que realizó la desmovilización.

${ }^{33}$ Peralta Ramos, op.cit., 18.

34، A diferencia de la realizada en los países que hoy son desarrollados, esta industrialización comienza siendo altamente intensiva en capital, respondiendo (...) a necesidades que no se derivan del nivel alcanzado por la acumulación interna de capital". Ibid., 21.
} 
redistribución del ingreso ${ }^{35}$, hasta aquella etapa en la cual para restituir la amenazada tasa de ganancia se hizo necesario reemplazar fuerza de trabajo por capital, caracterizándose por la intensificación de la explotación ${ }^{36}$.

La aceleración del cambio tecnológico en los países desarrollados, que consolidó la nueva etapa del imperialismo, coincidió con el desarrollo de la fase de la acumulación local que requería del ingreso masivo de capital extranjero y la importación de maquinaria e insumos industriales ${ }^{37}$. De modo que la alianza de clases entre fracciones de la burguesía y los trabajadores, que caracterizó al período peronista, se quebró y fue reemplazada por una nueva compuesta por la burguesía industrial, el capital extranjero y la oligarquía terrateniente. Se configuró, así, un enfrentamiento antagónico entre el capital y el trabajo.

La nueva etapa cursada por la acumulación de capital en Argentina y la configuración de las alianzas y enfrentamientos de clases, hizo imposible la asimilación política del grueso de la clase obrera argentina. En las etapas anteriores hubo "condiciones estructurales para una política distributiva", que fue sostenida y reclamada políticamente por la mayoría de la clase obrera desde el peronismo y le permitió, en su momento, canalizar la voluntad de participación política, desarrollando masivamente una acción de tipo reformista. Por el contrario, en la tercera etapa de la acumulación de capital en Argentina, la imposibilidad de una política distributiva y la necesidad de intensificar la explotación (a través del reemplazo masivo de fuerza de trabajo por maquinaria) condenaron a la inviabilidad a este tipo de acción reformista y abrieron paso al desarrollo de una política revolucionaria orientada por la conciencia de los intereses históricos de la clase obrera $^{38}$.

De modo que las bases para el desarrollo del proceso de movilización política que protagonizó la clase obrera en la Argentina de la década de 1970, estarían dadas por los cambios en el proceso de acumulación que coincidieron y se impusieron junto con la consolidación de la etapa desplegada por el capital imperialista.

La perspectiva de enfocar en los movimientos desplegados por la acumulación global del capital para analizar el curso seguido por la acumulación dentro del espacio nacional y las condiciones en que se desenvolvió el enfrentamiento entre las clases sociales, es desarrollado para el análisis del proceso de movilización y desmovilización política (aunque sin adherir a la explicación del imperialismo y la dependencia tecnológica) de la década de 1970 por los diversos trabajos de Ianni ${ }^{39}$ en los últimos años ${ }^{40}$. tecnologías avanzadas para restituir la ganancia a un nivel aceptable.’'Ibid., 128.

38،Si bien tanto en la primera como en la tercera etapa (...) existe una voluntad de participación en el sistema por parte de la clase obrera, sólo en el primer caso ésta aparece como un objetivo legítimo para el conjunto de la clase obrera. (...) En la tercera etapa, no hay condiciones para una política reformista, aunque sí para una política revolucionaria. (...). Por primera vez en nuestra historia existen condiciones estructurales para la aparición a nivel social de la conciencia de clase". Ibid., 174-175.

${ }^{39}$ Valeria Ianni, "La relación capital-trabajo en la empresa Ford motor Argentina (1959-1963)", en VI Jornadas de Sociología de la UNLP, La Plata, 2010a. Valeria Ianni, "La industria automotriz argentina en la crisis de mediados de los setenta", en memorias de las III Jornadas de Economía Crítica, Rosario $2010 \mathrm{~b}$.
} 
Sintéticamente, allí se plantea que para profundizar el análisis de los agudos cambios experimentados por el proceso social argentino en 1976 es necesario agregar el curso seguido por la crisis del capital y la lucha de clases a escala global a las variables clásicas utilizadas para su estudio (las acciones políticas de los diversos actores -Estado, clases, etc. $)^{41}$. Las transformaciones experimentadas por el capitalismo global, expresadas en la crisis de mediados de los `70, que modificaron la correlación de fuerza entre las clases, impusieron una redefinición del proceso de acumulación de capital y en la lucha de clases en la Argentina. De modo que, desde esta perspectiva, hacer abstracción de tales transformaciones limita la capacidad de explicación del proceso estudiado localmente ${ }^{42}$.

Esas transformaciones, realizadas en la segunda mitad de la década de 1970, significaron un cambio de fase en la acumulación global de capital, pasando de los "años gloriosos" de la segunda posguerra al neoliberalismo. Este cambio implicó también el fin del "acuerdo" en que había cristalizado la relación entre las clases. La expansión de la acumulación en la posguerra, basada en el crecimiento constante de la composición orgánica del capital, comenzó a resentirse al disminuir la velocidad en el aumento de la productividad del trabajo, y con ella la tasa de plusvalor, desde mediados de la década de 1960. De este modo se profundizó la tendencia decreciente de la tasa de ganancia que caracterizó la crisis general de esos años ${ }^{43}$. A su vez el "acuerdo de posguerra entre las clases", que había integrado institucionalmente a los sindicatos a cambio de salarios crecientes durante la expansión económica, comenzó a operar como un límite a los intentos de restituir la rentabilidad. El ascenso de la lucha de clases (desde el ausentismo y el sabotaje hasta las ocupaciones y movilizaciones de masas) protagonizado por los trabajadores en EEUU y Europa occidental, constituyó un ataque sobre la tasa de ganancias

Valeria Ianni, "La acción sindical en el marco de las negociaciones colectivas en Ford Motor Argentina durante la segunda etapa de la industrialización por sustitución de importaciones.", en 10 Congreso Nacional de Estudios del Trabajo, Buenos Aires, $2011 \mathrm{~b}$.

${ }^{40}$ El desarrollo de esta perspectiva tiene como objeto específico de indagación al sector de la industria automotriz, el cual -mediante la acción de los trabajadores y los representantes de los capitales automotricesocupó un lugar protagónico en el proceso de movilización y represión política del período. Sebastián Guevara, op.cit.. Ianina Harari y Sebastián Guevara, "Los efectos de la política represiva de la dictadura militar sobre la acción obrera: un análisis de los conflictos en Mercedes Benz entre 1973 y 1983.”, en e-l@tina Revista electrónica de estudios latinoamericanos $\mathrm{V}^{\mathrm{o}} 13 \mathrm{~N}^{\mathrm{0}} 50$, Buenos Aires, 2015.

${ }^{41}$ Ianni, 2010b, op.cit., 3.

42،"Es por todo esto que el análisis de la dictadura dentro de un estrecho marco nacional impide captar la profundidad de los cambios que estaban teniendo en el capitalismo a escala global y que imponen tanto una redefinición en la articulación entre mercados internos y mercado mundial que había caracterizado a la posguerra, como del lugar de la Argentina en esa nueva conformación. Lo mismo debe señalarse respecto de la alteración de la correlación de fuerzas entre capital y trabajo a escala global; al recomponer la situación nacional dentro del proceso más amplio a nivel internacional no sólo se pueden reconocer los aspectos comunes que revistió el proceso de reestructuración capitalista en ambos espacios (...), sino además puede visualizarse de un modo más acabado la especificidad del modo en que el capital definió a su favor la lucha de clases en la Argentina durante la segunda mitad de los setenta." Ianni, 2011b, op.cit., 9.

${ }^{43}$ Ianni, 2010b, op.cit., 23. 
y el obstáculo principal a la recomposición de las condiciones favorables para la acumulación de capital -aunque no necesariamente implicó una amenaza revolucionaria ${ }^{44}$.

La acumulación de capital necesitaba desarrollar una reestructuración a escala global para salir de la crisis y para ello necesitaba imperiosamente modificar la correlación de fuerzas existentes entre las clases. Se configuró así el ataque sobre las organizaciones gremiales y políticas de la clase obrera que caracteriza a la fase neoliberal y que impuso la reestructuración capitalista disciplinando a los trabajadores, aumentando la productividad del trabajo y restableciendo las condiciones de rentabilidad.

La industrialización por sustitución de importaciones con inversiones extranjeras que se desarrolló en la Argentina en la posguerra, ligaba en forma contradictoria la acumulación local a la internacionalización del capital a escala global. Es decir que a su manera, desarrollo desigual y combinado mediante, la acumulación en Argentina seguía las tendencias generales de la acumulación de capital ${ }^{45}$ (tendencia a la expansión, incremento en la composición orgánica, aumento menor de la productividad del trabajo y con ello de la tasa de plusvalor, caída de la tasa de ganancia, etc.). Mientras que la movilización política masiva de la clase obrera hizo fracasar los intentos de "racionalización" que se quisieron implementar durante la dictadura militar de la "Revolución Argentina" (1966-1973). Estos intentos fracasados fueron perfilando formas más agudas para imponer el requerido disciplinamiento a la clase obrera ${ }^{46}$.

El tercer gobierno peronista se vio atravesado, así, por el estallido de la crisis internacional. El estallido estuvo inmediatamente antecedido por una fase de producción a toda marcha que determinó la suba general de los precios de las materias primas (el caso del petróleo hizo historia), que significó una reversión súbita de los términos del intercambio para la economía Argentina que, de ese modo, alimentó una expansión acelerada de la acumulación en los primeros años de la década del `70. Este aumento de la producción se realizó a través de la intensificación en el uso de la capacidad instalada y el crecimiento del empleo, lo que redundó en una caída de la productividad del trabajo y en un fortalecimiento de los trabajadores en la negociación salarial (afectando así la rentabilidad) $)^{47}$.

Simultáneamente la reestructuración que se estaba desplegando a escala global implicó una serie de transformaciones en el proceso productivo que, internacionalización del capital mediante, redundó en un aumento agudo en la escala de la producción así como en la productividad del trabajo. Las nuevas condiciones de producción imperantes en la

\footnotetext{
44 “Esta fuerza objetiva y subjetiva de los trabajadores impidió que los efectos sobre la rentabilidad del capital a causa del avance de la automatización se compensaran con un incremento de la tasa de plusvalor.(...) Las reivindicaciones que levantaban los trabajadores en los países centrales no eran en la gran mayoría de los casos revolucionarias, no contenían un cuestionamiento de la relación salarial en sí, pero sin duda superaron los conflictos exclusivamente centrados en la "puja salarial" que habían dado la tónica a la era "fordista"”. Ianni, 2010b, op.cit., 24.

45 "La similitud en la temporalidad de la crisis no fue una simple coincidencia sino que mostraba que la tendencia general de la acumulación en Argentina había seguido la misma tendencia que a nivel mundial." Ianni, 2010b, op.cit., 23.

${ }^{46}$ Ibid., 12.

${ }^{47}$ Ianni, 2011 b, op.cit., 7.
} 
acumulación de capital global agudizaron las dificultades ya existentes en el proceso local (cuyo desarrollo al ser desigual y combinado no podía resolver). De modo que la industrialización sustitutiva entró en una crisis terminal no por su estancamiento (o por una imposición política) sino por el cambio cualitativo que se produjo en la industrialización general $^{48}$.

La necesidad de reestructuración productiva se hizo mucho más urgente. El "Plan Rodrigo" constituyó el intento más agudo de ajustar la economía para restablecer las condiciones favorables para la valorización del valor durante el gobierno peronista. La oposición obrera en las jornadas de junio-julio de 1975 frustró el intento y puso en evidencia la profundidad de la crisis. La confluencia entre los trabajadores radicalizados y las organizaciones revolucionarias, oponía un límite severo a la reestructuración y parecía poner en cuestión el poder (la dominación política) ${ }^{49}$.

La salida local de la crisis requería restablecer las condiciones para la expansión de la acumulación de capital y la movilización política de la clase obrera se alzaba como obstáculo a esa salida. El terrorismo de Estado implementado por la dictadura militar desde marzo de 1976, redefinió las relaciones de fuerza entre el capital y el trabajo en la Argentina, dando curso a la racionalización y al ajuste del proceso local de acumulación a las condiciones imperantes a escala global ${ }^{50}$.

Estos argumentos permiten profundizar la complejidad en el análisis de los acontecimientos históricos al plantear explícitamente la necesidad de avanzar en la indagación conjunta de las distintas dimensiones del proceso social. Es decir que plantean que no se puede explicar el movimiento de la acumulación de capital haciendo abstracción de la lucha de clases, y viceversa. En el mismo sentido plantean que el movimiento de la acumulación local no se puede estudiar haciendo abstracción de su relación con el conjunto de la acumulación de capital a nivel mundial. Las divergencias, entre los dos planteos presentados, comienzan a la hora de definir más concretamente dicha relación: en un caso se plantea como una relación de dependencia entre países desarrollados y países explotados; mientras que en el otro se apela a la existencia de un desarrollo desigual y combinado de las tendencias generales del modo de producción capitalista.

Sin embargo esta profundización permite, para avanzar en su desarrollo, realizar una serie de observaciones críticas.

La más inmediata, respecto de la relación existente entre las etapas seguidas por el capital imperialista y las etapas cursadas por la acumulación de capital en Argentina: Peralta Ramos plantea la existencia de una coincidencia entre la coyuntura local y la internacional que a su vez expresa la coincidencia de intereses entre los actores sociales que dominan en esa nueva etapa. Ahora bien, la razón de tal coincidencia no aparece explicada en su planteo (¿responderá acaso a la casualidad histórica?). Más precisamente lo que está

\footnotetext{
48،Esto implicaba que la desigualdad que, como hemos visto, no había nivelado las condiciones de producción locales con la media imperante en los países centrales, se viera acrecentada no por el estancamiento de la economía local sino por el desarrollo cualitativamente más rápido de las potencias industriales.” Ianni, 2010b, op.cit., 12.

${ }^{49}$ Ibid., 25.

50، Como en todos los países capitalistas, la recuperación de las condiciones propicias para la valorización del capital requería de una redefinición orgánica de las relaciones de fuerza en contra del trabajo”. Ibid., 23.
} 
ausente en esa explicación es la unidad general que existe entre la acumulación global de capital y la local.

En el trabajo de Ianni la "similitud en la temporalidad" de la crisis general de mediados de los `70 -tanto a nivel global como local- aparece explicada como la expresión de que la acumulación en Argentina seguía la misma tendencia general que la mundial (o sea, más que una simple coincidencia). De modo que, en este caso, la unidad entre las dimensiones estaría dada por estas tendencias generales del modo de producción capitalista. Concretamente: la crisis de mediados de la década de 1970 expresó la tendencia decreciente de la tasa de ganancia, tanto a nivel local como global, y su resolución pasó por una profunda reestructuración productiva que solo pudo llevarse a cabo a través del avance de la clase capitalista en la lucha de clases.

Sin embargo, esta relación entre lucha de clases y acumulación de capital queda presentada de un modo ambiguo. Por momentos parece que es la fortaleza "subjetiva y objetiva" que la clase obrera consiguió con el acuerdo de posguerra la que ataca a la tasa de ganancia, obstaculizando el proceso de acumulación. Determinando el avance del capital en la lucha de clases como una reacción ante la fuerza obrera. Por el contrario, al plantear que la caída de la tasa de ganancia es una consecuencia de la dinámica misma de la acumulación del capital (del aumento de su composición orgánica y la caída relativa de la productividad), el avance del capital en la lucha de clases aparece determinado como una iniciativa propia para imponer nuevas condiciones de valorización que contrarresten la tendencia general de la rentabilidad a caer.

La dificultad para definir claramente la relación existente entre el proceso de acumulación y la lucha de clases, aparece también al analizar las formas concretas seguidas por el desenvolvimiento histórico de la crisis. En la acumulación global (EEUU y Europa occidental) la fuerza de la clase obrera aparece presentando características no revolucionarias, en clara diferencia con lo que sucedió en el proceso local donde la confluencia entre trabajadores radicalizados y organizaciones revolucionarias pusieron en cuestión el poder. Y va a ser esa característica revolucionaria en el proceso local el que determine la violencia terrorista con que el capital avance en la lucha de clases a través del gobierno militar ${ }^{51}$. Ahora bien, ¿por qué el proceso de crisis se desarrolló en un caso bajo formas revolucionarias y en el otro no? ¿Por qué en un caso convergió la clase obrera movilizada con organizaciones revolucionarias y en el otro no? Siendo que en ambos casos la tendencia general de la acumulación estaba en crisis por la misma razón y tenía a la reestructuración como forma común de resolverla. Podría pensarse que el desarrollo desigual y combinado del capitalismo en Argentina tiene elementos para aportar claridad. Sin embargo, como ya se planteó, el movimiento de la acumulación en el ámbito nacional, así como su crisis y la resolución de la misma presenta las mismas tendencias generales que a nivel general, de modo que el desarrollo desigual y combinado no parece tener un rol muy definido que ocupar aquí. Y aparece explícitamente afirmado cuando, discutiendo con el planteo que sostiene que a partir de 1976 se llevó a cabo un proceso de desindustrialización, se argumenta que: en el marco general de la crisis -y como tendencia normal de la reestructuración- se produjo un proceso de concentración y centralización del capital que

${ }^{51}$ Ibid., 25. 
conllevó la liquidación de los pequeños capitales; y que ese proceso no debe confundirse con la definición violenta -genocida- que tomó el avance de la clase capitalista en la lucha de clases $^{52}$. Es decir: por un lado el movimiento general del capital y por el otro la lucha entre las clases sociales.

Esta ausencia de claridad a la hora de definir la relación existente entre la unidad mundial de la acumulación de capital (las tendencias generales) y el recorte nacional, se vuelve a manifestar al analizar la conclusión que se desprende del argumento general. Este sostiene que: la crisis del capitalismo de posguerra, expresada como crisis de rentabilidad en 1975, se "resolvió" a través de la reestructuración impuesta por la clase capitalista en la lucha de clases; Que con dicha reestructuración se racionalizó la producción global mediante la profundización del proceso de internacionalización del capital; Y que la dictadura militar en Argentina fue la encargada de llevar a cabo "la drástica redefinición de la relación de fuerzas a favor del capital" necesaria para restablecer las condiciones para la acumulación local. Sin embargo, la nueva división internacional del trabajo que se consolidó a nivel global, desde fines de los años '70, no encontró en Argentina a un miembro protagonista. Sino que, por el contrario, el proceso local parece haberse reproducido sobre bases similares a las vigentes durante la segunda mitad del siglo XX, aunque con un tamaño claramente reducido ${ }^{53}$. Es decir que parece haber algo particular en la forma en que se desarrollan las tendencias generales del modo de producción capitalista dentro del ámbito nacional Argentino que este argumento no logra terminar de identificar.

Finalmente, el sostener que la dictadura militar modificó las relaciones de fuerza que permitieron "recomponer, expandir y avanzar" a la acumulación de capital en un "nuevo ciclo largo" "54 (¿nuevo modelo de acumulación?), adecuado a las nuevas condiciones globales, termina emparentando este argumento con los planteos analizados más arriba que sostienen que los actores sociales imponen los distintos modelos de acumulación de capital a través de su acción voluntaria ${ }^{55}$.

\footnotetext{
52،De allí que la situación creada por la lucha de clases a favor del capital es, en estas circunstancias, la condición para (a la vez que el resultado de) que el capitalismo pueda recomponerse, expandirse y avanzar en un nuevo ciclo largo de acumulación. El hecho de que la reestructuración del capitalismo condujera, como siempre ocurre bajo la lógica del capital, a la expulsión del mercado de una gran cantidad de capitalistas medianos y pequeños no debe confundirse con la definición violenta de la lucha de clases en contra de la clase obrera." Ianni, 2011b, op. cit., 5.

${ }^{53}$ Alejandro Fitzsimons y Sebastián Guevara, "Transnational Corporations and the Restructuring of the Argentine Automotive Industry: Change or Continuity?", en Greig Charnock y Guido Starosta (Edits.) The New International Division of Labour. Global Transformations and Uneven National Development, Londres, Palgrave Macmillan, 2016.

${ }^{54}$ Ianni, 2011 b, op. cit., 5.

${ }^{55}$ “O sea que a cada fase de la acumulación de capital, corresponde una determinada alianza de clases dominantes, alianza realizada en base a un interés común y que se expresa ideológicamente en un modelo de desarrollo, que sintetiza el modelo de acumulación que se quiere imponer a la sociedad." Peralta Ramos, op.cit., 70 (énfasis agregado).
} 


\section{Conclusiones}

A lo largo de este trabajo hemos presentado y puesto en discusión un conjunto de argumentos que son desplegados normalmente a la hora de explicar el contrastante curso seguido por las formas políticas en la Argentina entre 1973 y 1983. Más allá de las muy variadas diferencias que existen entre esos argumentos (desde las distintas dimensiones del proceso social donde ponen el foco cada uno de ellos, pasando por el diverso grado de sofisticación a la hora de sostener sus afirmaciones, hasta las disímiles pretensiones de alcance explicativo), el punto donde todos parecen confluir es en el papel determinante de la voluntad inmediata de los actores sociales a la hora de participar de los acontecimientos históricos. De ahí que las explicaciones recaigan, en última instancia, en: las imposiciones (por unas voluntades sobre otras) de "desvíos" o "paralizaciones" a los procesos de movilización política o, de "intereses y perspectivas de un nuevo bloque en el poder" o, de los "modelos de acumulación", de las interrupciones de "procesos de industrialización" por "revanchas clasistas", las "refundaciones" del capitalismo local, etc.

Esta voluntad, a su vez, no presenta mayor explicación de su existir que: la fuerza del sujeto en cuestión para imponer su voluntad en una indeterminada relación de fuerzas opuestas. Es decir que el conjunto de los argumentos analizados terminan coincidiendo en explicar, en última instancia, el movimiento del proceso social por las relaciones de fuerzas que se presentan entre las clases en su enfrentamiento.

Parafraseando a Engels -en su análisis sobre la "teoría de la violencia"- podría decirse que, según estos planteos, la burguesía domina en la lucha de clases e impone un determinado modelo de acumulación porque tiene la espada, es decir la fuerza.

Pero, ¿por qué no podría pensarse el caso contrario de que la clase obrera use un revolver y la supere en fuerza? De lo que se trata es de explicar de dónde saca uno la espada y por qué el otro no tiene aún un revolver ${ }^{56}$. Es decir, explicar ¿qué determina la relación de fuerza entre las clases?

Esta relación de fuerzas enfrentadas entre las clases, la lucha de clases, no deja de ser la forma histórica concreta mediante la cual se realiza la organización del proceso de vida social, es decir el proceso de producción capitalista ${ }^{57}$.

De modo que el curso que queda abierto, a partir del conjunto de observaciones críticas realizadas a las explicaciones existentes, es avanzar en el desarrollo de un argumento que tenga como punto de partida el reconocimiento de la forma histórica específica que tomó la organización del proceso de producción de la vida social. Si bien aquí no cabe realizar ese avance, si se puede hacer una presentación esquemática de los puntos de partida con que cuenta esta perspectiva desde la crítica de la economía política.

\footnotetext{
56،"El problema, repetimos, está exclusivamente en explicar el porqué de esas relaciones de dominio y esclavización"...Federico Engels, Anti Düring. La subversión de la ciencia por el señor Eugen Dühring, Buenos Aires, Cartago, [1878] 1973,147.

57 "En una palabra, el triunfo de la violencia se basa en la producción de armas y ésta, a su vez, en la producción en general y, por lo tanto en el "poder económico", en la "situación económica", en los medios materiales que están a disposición de la violencia.” Ibid, 136.
} 
En tanto que forma histórica especifica adoptada por el desarrollo de las fuerzas con que cuenta la sociedad humana para producir su vida, el modo de producción capitalista se desenvuelve como si no llevara consigo ningún límite a su necesidad de expandir el trabajo social general. De modo que la unidad de la acumulación de capital es por su contenido un proceso mundial ${ }^{58}$. Pero el despliegue del trabajo social general, el contenido del proceso, se realiza bajo una forma histórica también específica, a saber: como trabajo productor de mercancías, lo que es decir como trabajos privados y recíprocamente independientes que se organizan automáticamente a través del cambio ${ }^{59}$. Esta contradicción entre el carácter social del trabajo y la forma de privado en que se realiza, es la que determina que en su desarrollo histórico la unidad mundial de la acumulación de capital se despliegue a través de la competencia entre recortes parciales de la producción social. Los recortes nacionales tienen así determinado su carácter de ámbitos nacionales de acumulación de capital en los que toma forma dicho contenido mundial ${ }^{60}$. De modo que el análisis concreto sobre el movimiento de la sociedad argentina tiene que dar cuenta de esta relación de contenido y forma. Y que se pueda reconocer qué curso, qué transformaciones, qué movimientos se estaban desarrollando en la acumulación de capital en su unidad mundial y bajo qué forma se realizó en el recorte nacional argentino, de modo que en el proceso histórico concreto local se avance en reconocer su condición de momento del movimiento global.

Es, a su vez, esta forma históricamente específica de organizarse el trabajo social global, como trabajos privados e independientes que ponen en relación directa a los productos del trabajo y en relación indirecta a sus poseedores (relaciones de cosas entre personas y relaciones sociales entre cosas) la que determina a estos poseedores como la personificación consciente y voluntaria de su mercancía, que, en tanto portadora del valor, es su relación social ${ }^{61}$. En su desarrollo concreto como proceso de producción de plusvalía,

\footnotetext{
58 "La independencia personal fundada en la dependencia respecto a las cosas es la segunda forma importante en la que llega a constituirse un sistema de metabolismo social general, un sistema de relaciones universales, de necesidades universales, de capacidades universales." Carlos Marx, Elementos fundamentales para la crítica de la economía política (Grundrisse) 1857-1858, México D.F., Siglo Veintiuno editores, [1971] 2001, 85.

59 "Los objetos de uso sólo se convierten en mercancías porque son productos de trabajos privados, independientes los unos de los otros. El conjunto de estos trabajos privados forma el trabajo total de la sociedad. Y, como los productores sólo entran en contacto social al cambiar los productos de su trabajo, tenemos que los caracteres específicamente sociales de sus trabajos privados se manifiestan solamente dentro de este cambio. $\mathrm{O}$, lo que es lo mismo, los trabajos privados sólo se comportan, en realidad, como partes del trabajo social global a través de las relaciones que el cambio establece entre los productos del trabajo e, indirectamente entre los mismos productores. Ello hace que las relaciones sociales entre los trabajos privados aparezcan ante los productores como lo que son, es decir, no como relaciones directamente sociales entre personas en sus trabajos mismos, sino como relaciones de cosas entre personas y relaciones sociales entre cosas." Carlos Marx, El Capital. Crítica de la economía política.Tomo I. México, D.F.: Fondo de Cultura Económica, [1867] 2014, 73.

${ }^{60}$ Juan Iñigo Carrera, El capital: razón histórica, sujeto revolucionario y conciencia. Buenos Aires, Imago Mundi, 2013, 144-160.

61 "El poseedor de dinero, en cuanto representante consciente de este movimiento, se convierte en capitalista. Su persona o, mejor dicho, su bolsillo es el punto de partida y el punto de retorno del dinero. El contenido objetivo de la circulación - de la valorización del valor- es aquí el fin subjetivo que él persigue, y sólo funciona como capitalista o capital personificado, dotado de voluntad y de conciencia, en la medida en que el
} 
y por tanto de reproducción ampliada (acumulación) del capital, la organización del trabajo social determina la necesidad de la compra venta de la fuerza de trabajo por su valor y de la producción de plusvalía relativa a través de la socialización creciente del trabajo privado ${ }^{62}$. Ambos procesos toman cuerpo a través de la acción de las personificaciones del capital y de la mercancía fuerza de trabajo; no a título individual sino en el universo de esas personificaciones: la clase capitalista y la clase obrera. De modo que la acción política y la acción gremial de clase (con las voluntades que las guían en su inmediatez y las fuerzas con que cuentan para el enfrentamiento) aparecen determinadas como las formas concretas en que se desarrolla la relación social general ${ }^{63}$. Así, la lucha de clases (que incluye el despliegue del Estado como vehículo de esta ${ }^{64}$ ) se desarrolla como la forma concreta mediante la cual se organiza en conjunto la producción social mediante la acumulación de capital en tanto forma histórica específica del desarrollo de las fuerzas productivas de la sociedad $^{65}$.

Más sintéticamente, aún, el análisis de los acontecimientos históricos necesita partir de reconocer la unidad existente entre la acumulación de capital como proceso mundial que se realiza recortado nacionalmente y que desenvuelve su movimiento a través de la lucha de clases, para poder avanzar en su explicación concreta, es decir como síntesis de las múltiples determinaciones generales que se realizan en ellos ${ }^{66}$. De este modo las fuerzas que cada actor logra desplegar en los enfrentamientos, así como las voluntades inmediatas que los guían en su accionar, aparecerán como lo que son, es decir, no una revancha clasista inspirada en un resentimiento de clase o un intento de imposición de distintos modelos o de realizar refundaciones sociales, sino como las formas concretas en que existe y se organiza la producción social bajo el modo de producción capitalista.

Volviendo a parafrasear a Engels, podemos concluir que el desarrollo desde esta perspectiva permitirá, al conocimiento que organiza la acción, avanzar sobre una base firme, más libre en tanto conoce la necesidad que lo determina ${ }^{67}$.

único motivo propulsor de sus operaciones es la creciente apropiación de riqueza abstracta.” Carlos, Marx, [1867] 2014, op. cit.,141.

62 Ibid., 207-272, 281-452.

${ }^{63}$ Sebastián Guevara y Mariana Hirsch, "La acumulación de capital en Argentina post 2001: análisis de límites y perspectivas desde sus expresiones en el movimiento sindical.” en IV Jornadas Internacionais de Problemas Latino-Americanos, Foz de Iguazú, 2014.

${ }^{64}$ Gastón Caligaris, "Clases sociales, lucha de clases y Estado en el desarrollo de la crítica de la economía política”, en Gastón Caligaris y Alejandro Fitzsimons (comp.) Relaciones económicas y políticas: aportes para el estudio de su unidad con base en la obra de Karl Marx, FCE-UBA, Buenos Aires, 2012.

65 "La lucha de clases es la forma concreta necesaria de realizarse la unidad de la organización del proceso de metabolismo social cuya forma más simple es la relación indirecta de acumulación de capital, tanto en la reproducción inmediata de esta como en la necesidad histórica que la misma lleva en sí de aniquilarse en una forma social superior a través de su propio desarrollo.” Juan Iñigo Carrera, “Acerca del carácter de la relación base económica - superestructura política y jurídica: la oposición entre representación lógica y reproducción dialéctica" en Caligaris y Fitzsimons, 2012, op. cit., 15.

${ }^{66}$ Carlos Marx, [1971] 2001, op. cit., 21.

67 "La libertad no reside en la soñada independencia de las leyes naturales, sino en el conocimiento de estas leyes y en la posibilidad que lleva aparejada de hacerlas actuar de un modo planificado para fines determinados. Y esto rige no sólo con las leyes de la naturaleza exterior, sino también con las que presiden la existencia corporal y espiritual del hombre: dos clases de leyes que podremos separar a lo sumo en la idea, 


\section{Bibliografía}

Facundo Aguirre y Ruth Werner, Insurgencia Obrera en la Argentina 1969-1976. Clasismo, coordinadoras interfabriles y estrategias de la izquierda, Buenos Aires, Ediciones IPS, 2009.

Guillermo Almeyra, "La clase obrera en la Argentina actual" en Alberto Pla, Guillermo Almeyra, Alberto Spagnolo, Oscar Cismondi, Héctor Capraro, Roberto Steso, Alejandro Dabat y Adolfo Gilly, La decada tragica. Ocho ensayos sobre la crisis argentina 19731983, Buenos Aires: Tierra del Fuego, 1984.

Eduardo Basualdo, Sistema político y modelo de acumulación en la Argentina, Bernal, Universidad Nacional de Quilmes Ediciones, 2001.

Eduardo Basualdo, Estudios de Historia Económica Argentina: desde mediados del siglo XX a la actualidad, Buenos Aires, Siglo Veintiuno editores, 2010.

Victoria Basualdo. "Los delegados y las comisiones internas en la historia argentina: 19432007', en Daniel Azpiazu, Martin Schorr y Victoria Basualdo, La industria y el sindicalismo de base en la Argentina, Buenos Aires, Cara o Ceca, 2010.

Gastón Caligaris, "Clases sociales, lucha de clases y Estado en el desarrollo de la crítica de la economía política", en Gastón Caligaris y Alejandro Fitzsimons (comp.) Relaciones económicas y políticas: aportes para el estudio de su unidad con base en la obra de Karl Marx, FCE-UBA, Buenos Aires, 2012

Héctor Capraro, Oscar Cismondi, Roberto Esteso y Alberto Spagnolo, "Argentina: economía y política en los años setenta”, en Alberto Pla, Guillermo Almeyra, Alberto Spagnolo, Oscar Cismondi, Héctor Capraro, Roberto Steso, Alejandro Dabat y Adolfo Gilly, La decada tragica. Ocho ensayos sobre la crisis argentina 1973-1983, Buenos Aires: Tierra del Fuego, 198.

pero no en la realidad. Por consiguiente, el libre arbitrio no es, según eso, otra cosa que la capacidad de decidir con conocimiento de causa. Así, pues, cuanto más libre sea el juicio de una persona con respecto a un determinado problema, tanto más señalado será el carácter de necesidad que determine el contenido de ese juicio; en cambio, la inseguridad basada en la ignorancia, que elige al parecer, en forma caprichosa entre un cúmulo de posibilidades distintas y contradictorias, demuestra precisamente de ese modo su falta de libertad, demuestra que se halla dominada por el objeto que pretende dominar.” Federico Engels, [1878] 1973, op. cit., 95. 
Federico Engels, Anti Düring. La subversión de la ciencia por el señor Eugen Dühring, Buenos Aires, Cartago, [1878] 1973.

Alejandro Fitzsimons y Sebastián Guevara, "Transnational Corporations and the Restructuring of the Argentine Automotive Industry: Change or Continuity?", en Greig Charnock y Guido Starosta (Edits.) The New International Division of Labour. Global Transformations and Uneven National Development, Londres, Palgrave Macmillan, 2016.

Adolfo Gilly, “Argentina después de la dictadura (Democracia, reorganización obrera, proyecto socialista)" en Alberto Pla, Guillermo Almeyra, Alberto Spagnolo, Oscar Cismondi, Héctor Capraro, Roberto Steso, Alejandro Dabat y Adolfo Gilly, La decada tragica. Ocho ensayos sobre la crisis argentina 1973-1983, Buenos Aires: Tierra del Fuego, 1984.

Adolfo Gilly, "Las Malvinas, una guerra del capital” en Alberto Pla, Guillermo Almeyra, Alberto Spagnolo, Oscar Cismondi, Héctor Capraro, Roberto Steso, Alejandro Dabat y Adolfo Gilly, La decada tragica. Ocho ensayos sobre la crisis argentina 1973-1983, Buenos Aires: Tierra del Fuego, 1984.

Sebastián Guevara, "Conflictos obreros en la industria automotriz argentina: análisis de la acción obrera en la planta de Ford antes y después del golpe militar de 1976”, en VIII Congreso ALAST, Buenos Aires, 2016.

Sebastián Guevara y Mariana Hirsch, "La acumulación de capital en Argentina post 2001: análisis de límites y perspectivas desde sus expresiones en el movimiento sindical.” en IV Jornadas Internacionais de Problemas Latino-Americanos, Foz de Iguazú, 2014

Ianina Harari y Sebastián Guevara, "Los efectos de la política represiva de la dictadura militar sobre la acción obrera: un análisis de los conflictos en Mercedes Benz entre 1973 y 1983.", en e-l@tina Revista electrónica de estudios latinoamericanos Vº13№50, Buenos Aires, 2015.

Valeria Ianni, "Un aporte al análisis de las causas de la ruptura histórica de marzo de 1976" en Memorias del IV Seminario Internacional Políticas de la Memoria, Buenos Aires, 2011a. 
Valeria Ianni, "La acción sindical en el marco de las negociaciones colectivas en Ford Motor Argentina durante la segunda etapa de la industrialización por sustitución de importaciones.", en 10 Congreso Nacional de Estudios del Trabajo, Buenos Aires, 2011 b.

Valeria Ianni, "La relación capital-trabajo en la empresa Ford motor Argentina (19591963)", en VI Jornadas de Sociología de la UNLP, La Plata, 2010a.

Valeria Ianni, "La industria automotriz argentina en la crisis de mediados de los setenta", en memorias de las III Jornadas de Economía Crítica, Rosario 2010b.

Juan Iñigo Carrera, El capital: razón histórica, sujeto revolucionario y conciencia. Buenos Aires, Imago Mundi, 2013

Juan Iñigo Carrera, “Acerca del carácter de la relación base económica - superestructura política y jurídica: la oposición entre representación lógica y reproducción dialéctica en Gastón Caligaris y Alejandro Fitzsimons (comp.) Relaciones económicas y políticas: aportes para el estudio de su unidad con base en la obra de Karl Marx, FCE-UBA, Buenos Aires, 2012

Hector Löbbe, La guerrilla fabril. Clase Obrera e izquierda en la Coordinadora de Zona Norte del Gran Buenos Aires (1975-1976), Buenos Aires, Ediciones RyR, 2009.

Carlos Marx, El Capital. Crítica de la economía política.Tomo I. México, D.F.: Fondo de Cultura Económica, [1867] 2014.

Carlos Marx, Elementos fundamentales para la crítica de la economía política (Grundrisse) 1857-1858, México D.F., Siglo Veintiuno editores, [1971] 2001.

Mónica Peralta Ramos, Etapas de acumulación y alianzas de clases en la Argentina (19301970), Buenos Aires, Siglo Veintiuno argentina editores s.a, 1972. 